\title{
"LA VIDA NO TIENE PRECIO": LA OPOSICIÓN A LA MINERÍA EN HONDURAS
}

\author{
Nick Middeldorp
}

Recibido: 08/07/2015 Aceptado: 02/12/2015

\begin{abstract}
Resumen
Este artículo documenta la oposición a la minería en Honduras, un país al borde del "auge minero", producto de la aprobación de la nueva Ley de Minería en abril del 2013. El movimiento surgió en la primera década del siglo XXI en respuesta al establecimiento de dos minas industriales, y enmarca el acceso al agua no contaminada como requisito para la vida y el sustento -un cuadro discursivo que se basa extensivamente en los impactos negativos de la operación a cielo abierto de Goldcorp en el Valle de Siria, Honduras, donde se registran graves problemas de salud-. Esto resuena fuertemente en las comunidades rurales, ya que dependen del acceso al agua para la continuación de sus modos de vida. En contraste, la industria extractiva y el Gobierno central no tienen este nivel de éxito al intentar convencer a las poblaciones locales de los potenciales beneficios de la minería. Debido a la falta de políticas para lograr un diálogo con el Gobierno central desde el golpe de Estado del 2009, el movimiento antiminero se ha enfocado en la búsqueda de oportunidades a nivel local, motivando a las comunidades a declarar sus municipios libres de minería a través de cabildos abiertos. Sucesivamente, donde medidas legales fallan en lograr el consentimiento de las comunidades para proyectos mineros, frecuentemente se empuja la "frontera extractiva" a través de la criminalización de oponentes y la amenaza de violencia.
\end{abstract}

Palabras clave: Honduras; minería; movimientos sociales; conflicto social; teoría del encuadre.

\begin{abstract}
This article discusses opposition to mining in Honduras, a country where mining has become a national development priority with the approval of the 2013 mining law. The anti-mining movement was born in the first decade of the 21th century as a response to the establishment of two industrial mines, and frames access to uncontaminated water as a requisite for life and livelihood. This discursive frame draws strongly from the experience with mining at the San Martín mine in the Valle de Siria, where serious health problems were registered. This frame resonates strongly with the rural communities, due to their dependence on access to water as part of their livelihoods. In contrast, the mining industry and the government are much less successful in convincing local inhabitants of the potential benefits of mining. Due to the lack of political opportunities to engage in lobby activities with the central government, the movement has focused on alternatives on the local level,
\end{abstract}


motivating communities to declare their municipalities free of mining through public referenda. However, where legal means to gain community's consent for mining projects fail, the extractive frontier is frequently pushed through the criminalization of opponents and threats of violence.

Key words: Honduras; mining; social movements; conflict; framing.

\section{Introducción}

La industria minera siempre ha expandido sus fronteras en la búsqueda de nuevos yacimientos de minerales con bajos costos de explotación (Svampa, 2011); territorios indígenas, parques naturales y el fondo del mar están sujetos a la industria extractiva (Canel et al., 2010), la cual aplica métodos controversiales como la minería de lixiviación de cianuro a cielo abierto. A su vez, en América Latina, muchos gobiernos consideran los minerales del subsuelo como un tesoro enterrado; quien lo excava "pone en marcha un ciclo virtuoso de cambio socio-económico" (Bridge, 2004: 225), lo cual lo convierte en un modelo de desarrollo mejor conocido como "extractivismo".

En el 2007, Bebbington y Valencia señalaron que Centroamérica sería la nueva frontera de la industria minera. La capital de Honduras, Tegucigalpa o "cerro de plata", fue fundada en la época colonial como ciudad minera; sin embargo, en el curso de los siglos esta industria dejó de ser un exportador significante de minerales (Newson, 1982). Luego de la destrucción total dejada por el Huracán Mitch en 1998, el Gobierno hondureño puso en marcha una nueva política minera que trató de revertir esta situación y establecer a Honduras como un país minero. La aprobación de la Ley General de Minería de 1999 -basada en la ley minera chilena (Aráoz, 2009; Moore, 2012)- abrió el paso a una controversial explotación nunca antes vista en Honduras: la mina de San Andrés en las montañas de Copán y la de San Martín en el Valle de Siria, ambas minas de oro a cielo abierto de capital canadiense. Por otro lado, nació un movimiento social que logró detener por completo la expansión de la industria minera en el país -hasta que el golpe de Estado deshizo sus logros.

Actualmente, Honduras presenta un caso donde la minería, politizada por el golpe de Estado en el 2009, de nuevo es fuente de una alta conflictividad. El Gobierno posterior al golpe -reelecto en noviembre del 2013- consideró la expansión de la industria extractiva como clave para el Plan Nacional de Desarrollo. Ante esto, se redactó - con apoyo técnico de la Cooperación al Desarrollo Oficial Canadiense- una nueva ley minera en el 2012, que entró en vigencia el 23 de abril de 2013. Casi un año después, en febrero del 2014, el periódico La Prensa reportó la realización de perforaciones prospectivas en 950 ubicaciones del país, y a partir de marzo del 2015, 380 concesiones mineras fueron otorgadas o se encuentran a la espera de ser aprobadas (INHGEOMIN, 2015). El Consejo de Minería e Industrias Extractivas Comercio e Inversión (COMICOIN) proclamó que el año 2015 sería conocido como el “año de la 
minería" (Latin America Advisor, 2015). Como consecuencia de este nuevo empuje de la frontera de recursos (Peluso y Lund, 2011) los oponentes a la minería -movimientos sociales ambientalistas e indígenas, ONG locales, comunidades rurales, así como sectores de la Iglesia católica- están movilizándose nuevamente. Con un recurso de inconstitucionalidad contra la Ley minera y a través de la movilización de las comunidades en defensa del territorio, se espera frenar la expansión de la minería.

En Guatemala, su expansión en el siglo XXI ha generado una conflictividad social considerable (e. g. Fulmer et al., 2008; Urkidi, 2011; Yagenova et al., 2010). Similar a la investigación de Urkidi sobre la resistencia a la minería en Guatemala (2011), este trabajo está enfocado en cómo el empuje de la frontera minera tiene respuesta -un empuje hacia atrás- entre las comunidades y los movimientos sociales. El estudio se inició un mes después de la aprobación de la nueva ley de minería, en mayo del 2013, con el objetivo de investigar por qué esta actividad genera tanta oposición en Honduras, cómo esta oposición se materializa y cuáles factores afectan la movilización social contra la minería.

Antes de esclarecer estas interrogantes se debe aclarar que el impacto de la mina San Martín en el Valle de Siria y el significado del agua -discursivo, simbólico y material- son indispensables para comprender la movilización contra la minería. Además, se explica por qué y cómo las estrategias del movimiento han cambiado después del golpe de Estado y por qué razón el movimiento no presta mayor atención al derecho legal y, con ello, organizar cabildos abiertos para declarar los municipios libre de minería.

La investigación de campo fue realizada entre mayo y noviembre del 2013. Durante la investigación, se participó en las actividades de una ONG y una red local: ASONOG y la MNIGR, ${ }^{1}$ que tienen una larga trayectoria de oposición a la minería. Además, se participó en reuniones, capacitaciones y movilizaciones comunitarias en distintas partes del país; ${ }^{2}$ así como foros en Honduras, El Salvador y Nicaragua, y se realizaron entrevistas a personas clave de la sociedad civil y estado en Honduras. Se visitaron a las minas de San Andrés y San Martín y también me entrevisté con funcionarios públicos, políticos y gerentes de la empresa canadiense Aura Minerals. La investigación fue complementada con un análisis de documentos: literatura académica, comunicados de prensa, cartas, videos, entre otros.

Este artículo está ordenado de la siguiente manera: comienza con una discusión del marco teórico del estudio: el empuje de la frontera de recursos, y los diferentes enfoques hacia los movimiento sociales. Segundo, se discute el caso de Valle de Siria -indispensable para comprender el movimiento antiminero en Honduras-. Tercero, se analiza cómo el movimiento antiminero da forma a su campaña y cuáles factores la influyen y por ultimo, se presentan las conclusiones de la investigación. 


\section{Sustento teórico}

El "complejo extractivista" -una adaptación del concepto "complejo de recursos" de Watts y Peluso (2014)-, se refiere a la configuración de fuerzas institucionales, legales y político-económicas contingentes que facilitan la expansión de la industria minera. Incluye los grupos de interés de la industria, el marco legal e institucional de la minería y otras normativas aplicadas.

La expansión de la industria minera requiere que el complejo extractivista establezca control del territorio. Según Peluso y Lund (2011), para tal fin se utilizan diferentes mecanismos interrelacionados: la legalización, la construcción de alianzas, el recinto y la violencia. El primero de estos se refiere a la aplicación del marco legal para legalizar la demanda de tierras (ej. el otorgamiento de concesiones mineras), mientras que el segundo describe el establecimiento de alianzas y acuerdos institucionales con actores estatales y no estatales. Por su parte, el recinto se refiere tanto a la separación física del territorio (ej. al poner alambre de púas) como a las restricciones legales que niegan y penalizan el acceso de "intrusos" y, finalmente, la violencia incluye la militarización del territorio y el uso del terror.

Este proceso implica una pérdida de control del territorio de las comunidades ahí ubicadas, lo cual forma parte de un impacto identificado como "acumulación por despojo"; concepto frecuentemente aplicado en el análisis de los impactos de la minería e introducido por Harvey (2004). La acumulación por despojo incluye la expulsión forzada de comunidades campesinas, la transformación de derechos de propiedad común hacia regímenes exclusivos (ej. la privatización de recursos naturales como agua y tierra) y la obstrucción de formas alternativas de producción (Harvey, 2004).

Las empresas mineras transnacionales, comúnmente, cuentan con programas de Responsabilidad Social Empresarial (RSE), también fomentados por los gobiernos de sus países de origen. No obstante, existe mucha crítica ante esto porque las compañías usarían la RSE por auto-interés, para asegurarse una "licencia social para operar" y frenar la regulación desde el Estado (Canel et al., 2010). Los beneficios recibidos solamente serían de apoyo a corto plazo y tenderían a favorecer a las élites locales (Canel et al., 2010; Coumans, 2010; Acosta, 2011), además de que las comunidades no tendrían derecho a rechazar actividades mineras en el proceso de consultas (Fulmer et al., 2008). Catherine Coumans (2010), con una fuerte crítica, argumenta que las empresas mineras operan con "impunidad efectiva" en países con estructuras débiles de gobierno. Ella escribe que la RSE es "cada vez más un movimiento controlado por las corporaciones cuyos abusos estaba destinado a frenar" $(2010,45)$.

Por lo tanto, diversos académicos señalan la necesidad de crear un marco legal e institucional más rígido, tanto en los países de operación como en los países de origen de las empresas mineras, con el fin de minimizar los impactos negativos sociales y ambientales y para generar un impacto positivo (Bebbington et al., 2007; Canel et al., 2010; 
Coumans, 2010; Fulmer et al., 2008. Sin embargo, en la práctica la voluntad política o la capacidad de control, con frecuencia están ausentes (Bebbington, 2012; Canel et al., 2010; Coumans, 2010).

Como observa Anthony Bebbington, "la industria extractiva produce ambos: una riqueza increíble, y destrucción al mismo tiempo" (2012: 5). También notó que "el conflicto social es un precursor necesario para lograr cambios institucionales socialmente y ambientalmente progresivos" (2012: 17). Ganancias monetarias altas versus la pérdida del sustento, desalojo y destrucción ambiental, son las luchas antimineras derivadas de los diferentes significados dados a lo que constituye el desarrollo. Por lo tanto, se puede analizar los conflictos mineros como arenas metafóricas donde se enfrentan diferentes ideas sobre el desarrollo, el papel de las comunidades y la valorización del medio ambiente.

Asi, los movimientos sociales, como expresión de este conflicto, tienen un papel clave, en especial porque poseen diversas características. Están creados como resultado de la ruptura de los límites de la compatibilidad en donde la acción tiene lugar (Melucci y Avitser, 2000: 518); son la representación pública de un conflicto existente, es decir, vehículos mediante los cuales las personas luchan para satisfacer sus necesidades colectivas (Zibechi, 2003), y expresan su autonomía y revalúan su identidad a través de rituales y la formación de solidaridad.

En esta investigación, se da un enfoque al análisis de los marcos discursivos (Benford y Snow, 2000) usados por los movimientos sociales para dar significado a su lucha y para convencer y movilizar a su público. La teoría de enmarque, como puente entre la teoría del discurso y la hermenéutica (el enfoque interpretativo), constituye una arista útil cuando se toma en cuenta la dualidad de la estructura. Asi pues en línea con la teoría de Giddens, sobre la dualidad de la estructura (1979), se puede afirmar que la construcción social de la realidad es creada por el agenciamiento humano y el pensamiento crítico, pero ocurre dentro de un marco de condiciones estructurales. Estas, a su vez, pueden estar sujetas a cambios inducidos por dicho agenciamiento.

Por su parte, Benford y Snow describen el "enmarcar" como "un fenómeno activo y procesual que implica agencia-miento y contención al nivel de la construcción de la realidad" (2000: 61). En otras palabras, implica la construcción social de una identidad compartida y una ideología; así como la formulación del problema y su solución propuesta.

Es por esto que, de interés particular son los marcos de acción colectiva usados por los movimientos sociales para movilizar el apoyo de su público. El marco discursivo principal del movimiento social-ideológico, simbólico o basado en la identidad compartida crea un espacio para articular marcos de acción colectiva más específicos (Steinberg, 1998). El éxito se alcanza si el marco tiene sentido para la gente que trata de convencer, necesita resonar, en contenido y en presentación genérica, con las experiencias cotidianas y personales que trata de movilizar en acción colectiva (Steinberg, 1998), pues de otra forma está destinado a fallar. 
En el contexto de esta investigación no se limitan los marcos hacia la acción intencionada, sino que también cubre la interpretación, o el significado de la industria extractiva y la acción colectiva en su contra, según el movimiento antiminero.

Por su parte autores como Urkidi (2011) y Escobar (2008) han planteado que los conflictos que involucran recursos naturales cuentan con dimensiones sociales y ambientales interconectadas, lo cual se expresa como tal en los marcos de acción colectiva de los movimientos sociales. Por ejemplo, se observa la importancia atribuida al agua como una lógica especialmente relevante para la movilización en el Perú. Además, se ajustan estos marcos para diferentes escalas, con el objetivo de movilizar apoyo de diferentes audiencias en distintos niveles (Haarstad y Floysand, 2006). En este sentido, los movimientos sociales ocupan una posición única como nexo entre lo local y lo global, pues pueden actuar como puente entre las comunidades locales y la sociedad civil internacional, al rearticular narraciones y percepciones locales hacia marcos ajustados para una audiencia nueva.

Sin embargo, también existen otros enfoques hacia los movimientos sociales, de los cuales se emplean dos para suplementar la perspectiva de encuadre: movimientos sociales que movilizan recursos (materiales, humanos, simbólicos y discursivos), para lograr sus objetivos, dentro de una estructura de oportunidades politicas (Gleditsch y Ruggeri, 2010).

Este último fue identificado por Benford y Snow (2000) como una variable contextual importante, así como cuadros y estrategias empleadas por los oponentes del movimiento. Como se va a mostrar en este artículo, estas dimensiones son especialmente importantes para considerar en el contexto de la movilización social contra la minería en Honduras.

\section{El Fundamento-Valle de Siria}

\section{Descripción de la mina}

La mina de oro San Martín está ubicada en una región llamada "Valle de Siria", en el departamento de Francisco Morazán, 70 kilómetros al noreste de Tegucigalpa. El Valle de Siria es una región de producción agrícola hogar, de muchas familias campesinas dependientes de la pequeña agricultura, así como del rubro ganadero. Las aldeas adyacentes a la mina: El Pedernal, (Nueva) Palo Ralo, Esquanito y San Miguel de Barrosa tienen una población total de alrededor de 4500 personas. La mina, cerrada desde el 2008, es clave para la formación y el simbolismo del movimiento antiminero en Honduras y en Centroamérica. Por lo tanto, el caso del Valle de Siria es indispensable para entender la resistencia a la minería. 
En 1999, la empresa Entre Mares, subsidiaria de la compañía estadounidense Glamis Gold, comenzó operaciones en el valle. Siete años después, fue adquirida por Goldcorp, de capital canadiense. La mina operaba dos sitios: Tajo Rosa (42,3 hectáreas) y Tajo Palo Alto (80,43 hectáreas), de donde se extrajeron 54 376,288 toneladas de oro durante su operación. Las rocas fueron procesadas a través de una plataforma de lixiviación a cianuro de 98,66 hectáreas, lo cual resulto en una producción total de 15,55 toneladas de oro puro. En aquel momento, las compañías mineras estaban obligadas a pagar una tasa municipal del 1 por ciento, lo que según el Instituto de Derecho Ambiental de Honduras representaba un total de USD 2570,750 US\$ (Herrera, 2013). La compañía recibió autorización gubernamental de usar hasta 800 litros de agua por minuto y su uso diario fluctuaba entre 100,00 y 227,400 litros, sacados de fuentes de agua locales.

La compañía organizaba fiestas y daba piñatas a los niños en un esfuerzo por ganar apoyo local, pero a pesar de esto un grupo de campesinos preocupados formó el Comité Ambiental de Valle de Siria (CAVS). Hoy en día, el CAVS es una organización clave del movimiento antiminero y, frecuentemente, recibe delegaciones de distintas partes de Honduras y de países vecinos para confrontarlas con el legado de la mina.

Una gira por (los impactos de la Minería en) el Valle de Siria

Josué, trabajador de una ONG local en el Aguán, advierte a las comunidades que enfrentan concesiones mineras e hidroeléctricas sobre los impactos de dichas industrias. Un día, acompañe a Josué en un viaje a la aldea rural de Abiscinia, en las montañas al sur de Tocoa, donde una empresa china tiene una concesión minera. Para ganar la confianza de la comunidad, ofreció viajes a China para sus líderes y transporte escolar para los niños. Josué ha programado una reunión con los líderes de la comunidad para confrontarlos con la realidad de la mina en el Valle de Siria.

Una vez en los cerros, Josué me comenta: "por acá, ya no hay Estado. No hay leyes. La única ley es la ley del arma". Se pone nervioso cuando se da cuenta de que nos está siguiendo un vehículo 4x4 con ventanas polarizadas. Me pregunta si puedo ver más claramente si el carro tiene algún logo, si hay chinos adentro. No distingo nada. Josué deja que el otro carro se le adelante... no pasa nada. Josué me explica que ha recibido amenazas de muerte y admite sentirse inseguro cada vez que observa un carro con ventanas polarizadas o una motocicleta con "dos tipos". ${ }^{3}$ Esta situación le impedirá seguir trabajando en el Aguán por mucho tiempo más.

Al llegar, los miembros del Patronato nos estaban esperando. Una vez en Tocoa, más personas se reúnen con nosotros: miembros de patronatos, Juntas de Agua, ${ }^{4}$ un bombero y un periodista. A la mañana siguiente, el grupo salen en un "rapidito" (buseta) alquilado. Josué tiene la primera palabra: 
Hay que ponerle los cojones, los testículos, ipara defender nuestros territorios! Si el pobre roba del rico, eso se llama violencia, verdad. Pero si el rico roba del pobre, eso se llama negociar. Con todas las promesas que hacen, jvan a engañar a la gente! (comunicación personal, 25 de junio del 2013).

Otro activista argumenta que las comunidades son los "verdaderos" propietarios del territorio y les recomienda registrar las fuentes de agua. "Nada vale más que el agua", concluye.

Nos reunimos con Eli, miembro del CAVS, quien nos acompañó al Valle. Según Eli, la desertificación en el lugar es consecuencia del uso del agua por la compañía. Observamos las aguas termales, usadas tanto para recoger agua, bañarse, lavar ropas, como para fines recreativos. La mina es invisible e inaccesible, pues la compañía usó la tierra excavada para crear un cerro artificial entre la comunidad y el pozo de la mina, mientras alambres de púas bloquean todo acceso.

Las grandes cantidades de agua usadas por la mina culminaron en una relación tensa con las comunidades. Al detrimento de los demás, ciertos individuos vieron oportunidades de negocio y comenzaron a comercializar las fuentes de agua en su territorio, vendiéndolas a la compañía. Según campesinos locales, el agua escaseó por las operaciones de la mina: 18 de los 22 pozos locales se secaron. En las palabras de Carlos Amador, portavoz del comité ambiental:

En verano, no hay nada de agua. Y antes de la mina sí había. Y ahora ya no hay. Porque la mina consume agua todo el día. Es un desastre porque el agua, que ahí está para el consumo, se perdió. El agua para los campesinos se perdió. El agua para la gente que vivía de la agricultura, iba a la mina. Entonces en cambio de mejorar las condiciones de vida, afectaba a la seguridad alimentaria de la población. Porque ahora en Valle de Siria, todos los productos alimentarios, se les trae desde Tegucigalpa. Y antes era de Valle de Siria, hasta Tegucigalpa. Y ahora es invierto, desde Tegucigalpa al valle de siria (comunicación personal, 25 de junio del 2013).

La mina creó hasta 140 empleos, un número que nunca balanceó el desempleo causado por la caída de la producción agrícola, razón por la cual varias familias campesinas migraron a Tegucigalpa o a los Estados Unidos (Herrera, 2013). En respuesta a la pérdida de agua, la compañía construyó un pozo para la comunidad de El Pedernal. Sin embargo, se rumoraba que el agua estaba contaminada, por lo que la compañía lo derrumbó antes de que los inspectores de DEFOMIN pudieran investigarlo. Tiempo después construyó un estanque de agua, localizado en frente de las pilas de lixiviación. Sin embargo, su posición en frente del agua venenosa causaba desconfianza y muchas personas locales optaron por recoger el agua escaza de las quebradas.

Muchos vecinos del Valle de Siria sufrieron problemas de salud como manchas en la piel y problemas respiratorios, los cuales ellos mismos vinculaban a su exposición al agua contaminada. En el 2005, Goldcorp contrató a un dermatólogo para estudiar 
sobre los problemas de la piel en las personas del lugar. Su investigación concluía que eran asuntos comunes: relacionados con la pobreza y sin ninguna relación con la actividad minera (OXFAM, 2008).

Durante el trabajo de campo, diferentes personas nos mostraron sus manchas de piel y nos permitieron entrevistarlas. Entramos a una casa, en el lugar había un olor penetrante... Encontramos a un señor acostado en una cama, sus piernas estaban cubiertas en vendajes de color marrón y las partes descubiertas revelaban carne sangrando. Su única condición confirmada es la diabetes, que parece haber multiplicado los efectos de las manchas de la piel, un síntoma que comenzó a empeorar hace dos años. Una señora nos permite entrevistarla y tomar fotos de las manchas en su espalda y sus brazos, bajo la condición de no tomar fotos de su cara ni mencionar su nombre. Rodeada por el grupo, ella dice:

Aquí hay bastante gente con enfermedades de la piel. Tenemos casi todos problemas con la piel. Unos más que otros. Aquí en este barrio, aqui donde nosotros vivimos, hay aproximadamente como 30 casos. Ahí al otro lado vivía una familia y la hija de cinco años murió de cáncer. Mi vecina de 25 años murió de cáncer (comunicación personal, 25 de junio del 2013).

La niña de cinco años, llamada Leslie Yanitza, no murió de cáncer, pero fue diagnosticada con el síndrome de Werdnig-Hoffman (trastorno genético que causa parálisis muscular). La parte inferior de su cuerpo ya estaba paralizada cuando murió (Almendarez, 2011). Nadie en su familia tiene el síndrome, pero pruebas de sangre revelaron niveles de plomo y arsénico aumentados ${ }^{5}$, ambos capaces de causar mutaciones genéticas. Leslie era una de seis niños concebidos por trabajadores de la mina en un lapso de tres años de actividad minera. Tres fueron abortados durante el embarazo y dos no sobrevivieron su primer año (Bianchini, 2006).

En el 2006, el investigador italiano Flaviano Bianchini realizó muestras de sangre y agua en el Valle de Siria. Al recibir mensajes y llamadas amenazantes por haber tomado muestras de agua en comunidades afectadas por Goldcorp en Guatemala, huyó hacia Honduras para continuar su trabajo. En el Valle de Siria, Bianchini encontró niveles de arsénico y plomo alarmantes en las quebradas locales. Además de estos lugares, también tomó muestras de sangre de los habitantes de El Pedernal y Nuevo Palo Ralo, las cuales revelaron niveles alarmantes de los mismos materiales. En respuesta a los resultados de la investigación, Entre Mares publicó una declaración oficial en la cual afirmaba que las muestras de Bianchini faltaban al rigor científico.

En la siguiente casa que visitamos, nos mostraron informes de medicina forense del Ministerio Público, los cuales detallaban los resultados de una prueba de sangre realizada por el Estado en el 2007. El estudio reveló resultados opuestos a los de Bianchini y concluye: "ni un resultado sobrepasa los resultados de las referencias externas". Su contradicción con la investigación de Bianchini es interesante. Almendarez, uno de 
los líderes del movimiento, regularmente visita el Valle de Siria con una brigada médica, y opina que "más allá de la irresponsabilidad, participaron en un encubrimiento" (comunicación personal, 15 de julio del 2013).

En el 2009, Caritas, con apoyo de la ONG internacional CAFOD, invitó a investigadores de la Universidad de Newcastle. Su informe confirma una concentración alta de metales y drenaje ácido de minas en las aguas subterráneas (Jarvis y Amezaga, 2009), y recomienda a la compañía reparar las consecuencias ambientales de la contaminación causada por el drenaje ácido. Basado en el informe, la fiscalía del ambiente presentó demandas jurídicas en contra las gerentes de Entre Mares (Van De Sandt, 2009), demandas que fueron retiradas por razones desconocidas. Inspectores de DEFOMIN ${ }^{6}$ también encontraron una concentración de metales en el agua por arriba de los estándares aceptables y multaron a la compañía con un millón de lempiras (USD 50 000). La empresa negó toda responsabilidad y cuestionó los resultados de la prueba. Al fin, se dictaminó que DEFOMIN no colectó pruebas válidas. No obstante, en una entrevista (comunicación personal, 11 de octubre del 2013), el director del instituto ${ }^{7}$-en aquel momento fiscal general del ambiente- manifestó: "la mina de San Martín tiene un problema. Yo como funcionario no voy a esconder eso".

La mina afectaba a los dos géneros de forma diferenciada (Herrera, 2013). En las negociaciones sobre la reubicación del pueblo de Palo Ralo, la empresa solamente consultó con los "cabos de familia" (los hombres), quienes se convirtieron en trabajadores asalariados y se reporta un incremento en el uso de drogas. Además, por la contaminación de agua, las mujeres y niñas están expuestas a riesgos y problemas más grandes de salud, ya que tradicionalmente tienen la carga de responsabilidades como lavar ropa, mantener la higiene del hogar y cocinar.

El siguiente destino del grupo fue Nueva Palo Ralo - una aldea reubicada por la empresa-. Yo entrevisté a una señora anciana, quien tenía problemas en la piel y en su mano presentaba un mechón de pelo recién caído. Ella tenía su propia explicación para su padecimiento: "creo que fue el jabón que me puse", pero además tiene otras observaciones sobre la mina:

Una noche murieron como dieciséis vacas. Tomaron agua que venía de la mina. Después de la tormenta.

- ¿Cuál es su observación sobre la mina?

-Que nadie quería a la mina, pero pagaban bien para el terreno... Gente que tenía terreno, lo vendió (comunicación personal, 25 de junio del 2013).

Las vacas murieron después de que una tormenta tiró agua de las pilas de lixiviación en las quebradas. Además, la señora toca un nuevo asunto: los conflictos entre las partes implicadas, pues la gente que tenía terrenos (títulos de propiedad) los vendió por altas cantidades, mientras que otros mantenían vínculos comerciales con la compañía al 
venderle agua para la mina. Debido a esto, surgieron tensiones entre quienes se benefician de la mina, al establecer relaciones comerciales, y las personas perjudicadas. Un conflicto tenso surgió entre el CAVS y los transportadores de agua de la compañía, quienes desarrollaban una relación de negocios duradera con Entre Mares. Debían suministrar agua a la compañía y distribuir raciones de la misma a las comunidades, pero en una ocasión, durante una reunión del CAVS en una escuela primaria local, los transportadores rodearon la escuela, amenazaron con violar a las mujeres y matar a los hombres.

También ocurrieron otros actos de violencia, según relataron:

Entre Mares contrató para seguridad a un ex-miembro del Batallón 3-16, el reconocido escuadrón de la muerte que operó en tiempos de la aplicación de la Doctrina de la Seguridad Nacional en los años ochenta secuestrando, torturando, asesinando y desapareciendo personas consideradas como opositoras del régimen entonces vigente. A este guardia se indica como responsable de la tortura y asesinato de Rolando Gutiérrez, quien llegó buscando empleo a la mina y desapareció esa misma noche. Rolando Gutiérrez es hermano de un reconocido activista de la defensa de los derechos humanos (Herrera, 2013: 24).

El Dr. Almendarez formó el Movimiento Madre Tierra, el cual se convirtió en una de las plataformas líderes en la lucha contra Entre Mares. Realizaba investigaciones con los pobladores de Valle de Siria, denunciaba los impactos de salud y comenzaba a proveer apoyo médico, una práctica que se continúa hasta hoy. Sus esfuerzos contribuían para la "globalización" del caso, al atraer la atención de organizaciones internacionales como OCMAL (Observatorio de Conflictos Mineros de América Latina) y la TLAA (Tribunal Latinoamericano de Agua), un tribunal simbólico que juzgó a Goldcorp por la pérdida y contaminación de agua. Los opositores de Almendarez también destacaban su trabajo:

Las brigadas de salud y los trabajos de investigación que realizamos con el Movimiento Madre Tierra fueron valiosos para presentar el problema a la comunidad nacional e internacional, a tal grado que el gerente de la Empresa Minera amenazó con enviar a la cárcel al autor de este artículo y así mismo se recibieron varias amenazas a muerte por nuestra lucha en pro de los derechos humanos y de la justicia ambiental. Un archivo completo de nuestras investigaciones fue robado de nuestras oficinas dejando amenazas a muerte (Almendarez, 2006: s. p.).

Algunos miembros del Comité nunca recibieron protección del Estado, más bien estaban y están todavía siendo criminalizados y perseguidos.

\section{El simbolismo del Valle de Siria}

Según Josué, la excursión al Valle de Siria no es un "viaje turístico". Las promesas hechas por las compañías mineras son "puras mentiras" y "no se puede negociar 
con la vida". El Valle de Siria, más que ser un lugar dedicado a la minería, es un símbolo de resistencia y martirio. El movimiento antiminero, dentro y fuera de Honduras, activamente usa al Valle de Siria como punto central de referencia cuando se refiere a los impactos de la minería. Hay fotos de personas enfermas de Valle de Siria circulando por internet y los activistas las enseñan durante capacitaciones comunitarias sobre la minería. Así, se espera prevenir el mismo destino para otras comunidades que enfrentan concesiones mineras. La excursión de líderes comunitarios al Valle de Siria es un paso esencial en el rito para tener consciencia de las consecuencias de la minería y disposición para defender el territorio. El movimiento antiminero otorga este rol al Valle de Siria, también abrazado por el comité ambiental de Valle de Siria, como lo expresado por Carlos Amador en una entrevista: "Somos campesinos. Campesinos con la voluntad de lucha, de cuidar de proteger. Hoy en el día, estamos generando una voz para que las comunidades conozcan, para que no permitan que las empresas entren en las comunidades".

Goldcorp es una de las compañías mineras más grandes del mundo, pues opera en varios lugares de América. Ante esto, resulta importante para una empresa de esta magnitud cultivar una imagen pública positiva, razón por la cual en su sitio web (www.goldcorp.com) se puede leer el lema "la minería responsable y crear valor sustentable están al corazón de nuestro negocio". En su discurso, la compañía usa palabras como "prosperidad sustentable", "alianzas y oportunidades de negocio con pueblos aborígenes e indígenas", "inversiones comunitarias sustentables" y "desarrollo sostenible". Además, la compañía es miembro y participa en diversas organizaciones e iniciativas de responsabilidad social empresarial. ${ }^{8}$ Para resumir sus excelentes relaciones comunitarias, Goldcorp argumenta que

En Goldcorp, estamos comprometidos a hacer una diferencia positiva en las comunidades y los países donde estamos ubicados. Nos esforzamos por mejorar las circunstancias socio-económicas a través de contribuciones económicas, participación comunitaria, consultación comunitaria, apoyo de salud y educación, y patrocinio de eventos locales. Trabajamos en asociación con los cuerpos comunitarios, funcionarios del gobierno y otras partes interesadas para aumentar la comprensión de culturas, costumbres y valores, y para fomentar el diálogo constructivo y la confianza (Goldcorp, s. f.: s. p.).

Goldcorp presenta su proyecto de San Martín como un caso exitoso de reclamación ambiental post-cierre y desarrollo comunitario. En un video publicado en Youtube (2011) San Martín está presentado como un caso donde las comunidades locales -gracias al esfuerzo de la compañía- "siguen prosperando", a pesar del cierre de la mina. El video informa al espectador sobre el hotel de ecoturismo y proyectos ganaderos puestos en marcha por la Fundación San Martín, una caridad creada por la compañía después del cierre de la mina9 ${ }^{9}$ Similarmente, en un informe sobre minería 
en "países no desarrollados", los empleados de Goldcorp Roldan y Purvance (2012) escriben que la mina de San Martín dejó un "legado positivo" para las comunidades. Concluyen su informe con el siguiente mensaje: "la minería puede ser beneficiosa para las comunidades cercanas, la compañía y la industria minera en general" (10).

Puedo afirmar con certeza que nadie dudará que la minería es beneficiosa para la industria, pero bajo qué condiciones la minería puede ser beneficiosa para las comunidades, está sujeto de debate. No obstante, la compañía construye una imagen en que la minería es desarrollo: las comunidades rurales en "países no desarrollados" pueden prosperar gracias a la empresa minera extranjera. Las comunidades están reducidas a recipientes pasivos de ayuda, objetos de intervención. La caridad de la empresa es un seguro social que permite a las comunidades sobrepasar los impactos del cierre de mina.

Estas comunidades, en vez de ser recipientes agradecidos y pasivos de ayuda, mantienen que la mina ha contaminado su agua. No obstante, Goldcorp está mencionado en la lista de las corporaciones mas sostenibles de Canadá en el 2015 (Goldcorp, junio 2015), y tiene una posición en el Nasdaq Sustainability Index del 2015 (Goldcorp, diciembre 2015) y el Dow Jones Sustainability Index North America (Goldcorp, 2012). A pesar de la globalización del caso y la revelación de las mentiras corporativas, esta información no logra penetrar los muros del mercado de valores, donde se premia a Goldcorp por su conducta sostenible.

\section{Discursos y prácticas de resistencia}

\section{Un breve contexto histórico}

La oposición a la minería en Honduras es consecuencia de la problemática acerca de las minas de San Andrés y San Martín. Se formó un movimiento a nivel nacional que exigió una revisión de la ley minería por parte de la Corte Suprema -la cual declaró inconstitucional varios artículos de la ley. La plataforma más influencial dentro del movimiento antiminero era la Alianza Cívica por la Democracia (ACD). La capacidad de la ACD de movilizar miles de personas en bloqueos de carreteras la permitía crear una fuerte presión y ampliar sus oportunidades políticas al nivel nacional. Como es expresado por un activista: “La única manera que se queda al pueblo, es manifestar en las calles. En algunos momentos, los políticos solamente responden a través de la fuerza y a través de la presión" (comunicación personal, 3 de agosto del 2013).

La ACD detuvo el otorgamiento de nuevas concesiones mineras metálicas y motivó al presidente Zelaya para crear una comisión cuyo objetivo era redactar una nueva ley minera, que aumentaría los impuestos, prohibiría la minería a cielo abierto y el uso de cianuro, y pondría un límite al uso del agua. Asi pues, la ACD se convirtió en un movimiento social poderoso hasta que sus líderes fueron forzados, 
por amenazas a su vida y juegos políticos, a abandonar el movimiento; y hasta que el golpe de Estado sumió al país en el caos. Zelaya fue expulsado del país, la ley nunca fue debatida en el congreso y el gobierno interino comenzó a otorgar nuevas concesiones mineras para contrarrestar la crisis económica agravada por el golpe. El grupo de interés en la industria se aprovechó de la situación, argumentó que por la ausencia de una ley minera el país estaba perdiendo tres billones de dólares anuales (Jamasmie, 2012).

La nueva ley minera fue aprobada en un ambiente politizado y sin contar con un consenso en la sociedad civil. La CNRAH ${ }^{10}$-actualmente la mayor plataforma de organizaciones críticas a la minería- eventualmente abandonó las negociaciones. La desconfianza mutua también fue expresada por Donaldo Reyes Avelar, diputado y presidente de la comisión de minería del congreso nacional:

Esto quiere decir que ellos viven para sacar pisto, robando. Es ilógico que se molesten, no tiene sentido. Ellos lo hacen por eso, mira (un gesto de recibir billete). Generalmente estas personas que andan metidas en esta oposición son personas de izquierda, que de repente forman parte de un partido por aquí (comunicación personal, 11 de octubre del 2013).

El diálogo con el gobierno central ya no es visto como una opción. La asociación del sector minero, ANAMIMH, ${ }^{11}$ es propietario de un canal de televisión nacional que proyecta la minería como la salvación de Honduras. La ley minera establece un vínculo directo entre las empresas mineras y las fuerzas estatales de seguridad, a través de una "taza de seguridad". Entonces, la lucha antiminera está caracterizada por importantes inequidades en recursos políticos y económicos entre la industria minera y el movimiento antiminero.

Debido al cierre de oportunidades políticas a nivel nacional, las acciones del movimiento antiminero se enfocan en la movilización de comunidades que enfrentan concesiones mineras. Además, con el crecimiento de actividad minera en el país, el número de organizaciones involucradas en la lucha antiminera también ha crecido significantemente. "No queremos mártires", comenta Gabriela, técnico de ASONOG, pues se intentan declarar las municipalidades libres de minería, antes de que las empresas mineras entren. Incluso, la nueva estrategia se he mostrado exitosa: más de 20 municipalidades ya han sido declaradas libre de minería ${ }^{12}$ a través de cabildos abiertos, los cuales han sido reconocidos por los gobiernos locales, pero sin validez legal.

\section{Lucha de cuerda con las comunidades}

Para movilizar la base, organizaciones como el MADJ ${ }^{13}$ y la MIGR ${ }^{14}$ establecen contacto con instituciones e individuos importantes como Patronatos y Juntas de Agua de comunidades que enfrentan concesiones mineras. Organizan capacitaciones sobre el surgimiento del modelo extractivista después de Mitch; la historia del movimiento 
antiminero, la ley de minería; los impactos ambientales y sociales de la minería; la complicidad del Estado y la parcialidad de INHGEOMIN, ${ }^{15}$ la expansión china en Honduras, los derechos ciudadanos; y cómo oponerse a una mina de manera legal y pacífica. Ademas, se enseñan fotos de la demolición de la iglesia y del cementerio de San Andrés -marcado como la destrucción del patrimonio- y documentales de la lucha antiminera en Crucitas, Costa Rica; se cuestiona aceptar dinero o servicios de compañías mineras al costo que la destrucción ambiental; se critica la cantidad de impuestos pagados, la capacidad de una compañía de generar empleo sostenible; y se cuestiona la capacidad del Estado para controlar si la compañía no explota en secreto otros metales además de los reportados. Sin embargo, de todos los argumentos, ninguno es tan eficaz como el argumento de que la minería es una amenaza para el agua y la vida -ilustrado por los impactos de salud en la población de Valle de Siria-.

Las cenas compartidas y los rezos son actos que esencialmente sirven como "rituales de solidaridad" (Lichterman, 1998) entre activistas y pobladores. Además, se cantan canciones de protesta como "el pueblo unido jamás será vencido". Otra canción simbólica que se reproduce es

No puedes comprar el sol

No puedes comprar la lluvia

(Vamos dibujando el camino)

(Vamos caminando)

No puedes comprar mi vida

Mi tierra no se vende

\section{Latinoamérica, Calle 13}

El discurso igualitario (nosotros el pueblo versus "los grandes") ayuda en la formación de solidaridad. Los líderes comunitarios están motivados a crear un comité ambiental o de defensa y cuando los recursos lo permiten, viajan al Valle de Siria.

Ahora bien, son dos discursos radicalmente opuestos que tratan de ganar el favor de las comunidades, que según la ley minera deben dar su permiso para la fase de explotación a través de una consulta comunitaria. Esto ha dado al movimiento antiminero un sentido de urgencia para llegar a las comunidades. Según el primer discurso, existe una preocupación comúnmente expresada de que las comunidades que no están conscientes de los peligros de la minería - por pobreza y falta de conocimiento- puedan aceptar un proyecto minero que últimamente ha traído más daños que beneficios. Como bien afirma un miembro del MADJ:

... la gente tiene que estar informa, es decir, no solo lo que manifiestas los mineros, y digamos que tienen el derecho a su planteamiento, pero por otro lado la gente tiene que estar informada de todo lo que trae la minería. Ya va, una consulta o una asamblea, si esta gente no está bien 
informada rápidamente puede manifestarse en promoción de la minería sin saber todo el contexto (comunicación personal, 22 de agosto del 2013).

"Prácticamente es una guerra", me comenta un funcionario de INHGEOMIN. Él está consciente del trabajo del movimiento antiminero en las comunidades y argumenta que este abusa de la falta de conocimiento sobre los beneficios de la minería:

Nosotros creemos que ya es un modus vivendi - una forma de vida de estas organizaciones. A conseguir fondos. Es en alguna manera de llamar la atención y crear anticuerpos en contra la actividad minera en el país. Que no son fundados, científica real. El problema con esto es que la gente de este país lastimosamente no es educada, como para tener una capacidad de decir "sí es cierto o no es cierto". Entonces lo que hace esto es crear miedo en la población, miedo de un proyecto minero. Miedo a cambio. Y hay mucho rechazo dentro las comunidades. Muchas de las comunidades dicen "yo prefiero estar en mi condición de pobreza, sin cambio", por todo este trabajo que han realizado estas organizaciones ambientalistas en las comunidades (comunicación personal, 22 de agosto del 2013).

Por lo tanto, este funcionario del INHGEOMIN recomienda a las compañías mineras ganar apoyo local para sus proyectos lo más pronto posible. Estas empresas entran a las comunidades con discursos de prosperidad, buenos salarios y otros beneficios y ofrecen giras al extranjero y trabajos bien pagados a los líderes. La minería está presentada como racional: fundada y salvaguardada por el conocimiento científico, la minería representa el camino hacia el progreso. Las organizaciones ambientales -parásito de la industria minera- cultivan temores no fundados y sabotean el desarrollo mismo. El personal de INHGEOMIN está muy consciente de la reputación negativa del sector minero, por lo cual están haciendo esfuerzos para mejorar la imagen de la industria:

En la actualidad nosotros tenemos un canal en la televisión, un canal nacional, en el cual todos los miércoles hablamos de cosas relacionadas con la minería, prácticamente la gente comienza a ver que la minería es un proceso que está involucrado con nuestras vidas y que no podemos vivir sin extracciones mineras. Porque los discursos que tienen estos grupos ambientalistas es cero minería. Cero minería vendría a ser un retroceso en la sociedad (comunicación personal, 22 de agosto del 2013).

Tres años después de que CESPAD (2011) encontró que más de un 90 por ciento de los hondureños rechaza la minería a cielo abierto, aún está por verse con un nuevo censo si este porcentaje ha disminuido significantemente debido a la campaña de publicidad minera. No obstante, en los seis diferentes encuentros comunitarios sobre la minería en que participé, las personas participantes expresaron la necesidad de defender su comunidad, sus fuentes de agua y su territorio de la industria minera. 


\section{El éxito del movimiento con las comunidades}

La experiencia de la mina San Martín marcó el discurso de oposición a la minería. Como afirmó Carlos Amador, un representante del CAVS:

... y por eso te digo, si eso da inseguridad alimentaria, si esto ha generado desempleo campesino, si eso ha provocado problemas de salud, problemas de producción, ¿de qué estamos hablando? ¿De qué desarrollo estamos hablando? Nosotros decimos un desarrollo patas arriba. O sea, estamos con los pies acá y la cabeza acá. Sí, hay un desarrollo. Para la gran corporación transnacional. Muchísimo dinero. ¿Y el país? Me deja problemas ambientales. Problemas de salud (comunicación personal, 25 de junio del 2013).

Se enmarca la minería como un saqueo neocolonial de los recursos hondureños, pues la riqueza mineral está a cargo de empresas extranjeras que casi no pagan impuestos, mientras el país debe manejar los daños. Pese a esto, el discurso antiminero va más allá de lo que la industria minera considera "nacionalismo de recursos", es decir, proteger aquellos recursos que han sido adquiridos por una empresa extranjera. Por ejemplo, en el Valle de Siria la minería se presenta como una amenaza a un ambiente sano para la vida. De hecho, fue en este lugar donde, por los impactos de salud provocados por la mina, nació la frase popular del movimiento "la vida vale más que el oro".

Esta frase expresa mucho más que un nacionalismo de recursos. Varios activistas prefieren emplear el término "bienes naturales", en lugar de "recursos naturales", pues este concepto implica algo que se puede extraer, tener y vender. “¿Cuánto vale tu río? ¿Cuánto cuesta tu bosque? ¿Cuánto cuesta tu suelo? ¿Cuánto de oro tiene? ¿Cuánto de plata tiene?", pregunta Carmen -miembro de la MIGR- retóricamente en una reunión comunitaria. El movimiento antiminero argumenta que un ambiente sano (agua potable, bosque y tierra para cultivar) es un derecho básico para el bienestar del ser humano. Resulta imposible poner un precio al bienestar. Por lo tanto, no se puede dar un precio a los bienes naturales que necesita toda persona para vivir: agua, bosque y tierra.

Por su parte, Dr. Almendarez cuestiona la separación conceptual en la realidad construida entre la sociedad y la naturaleza, en la cual la "naturaleza", como recurso explotable, está sujeta a la "sociedad" y proyecta su perspectiva en las comunidades indígenas al argumentar que muchas personas necesitan aprender de estos grupos:

Ellos ven la unidad de la tierra en una relación comunitaria. En la idea de tierra, en la idea del territorio...Fijense bien, si planteamos de la relación entre sociedad y naturaleza, los indígenas, ellos dicen que hay una relación. Una relación sagrada entre la gente de las comunidades y la madre tierra. Que si se rompen esa relación, viene, prácticamente la muerte y la enfermedad. Esto es. El saber ancestral del ambiente; tenemos que analizar la relación sociedad naturaleza. 
El ambiente no está fuera de nosotros. El problema es la separación en la realidad de sociedad naturaleza (comunicación personal, 11 de agosto del 2013).

Quisiera evitar esa visión determinista de que las comunidades rurales, tanto indígenas como campesinas, independiente de sus conceptualizaciones de la realidad, simplemente tienen una fuerte dependencia hacia los bienes naturales para su sustento y no son entidades homogéneas.

Para volver al caso de Valle de Siria, después de que Entre Mares abrió su mina de San Martín en aquella zona, el agua se convirtió, por primera vez, en un recurso escaso y comprable. Diferentes personas comenzaron a comercializar este líquido. SosaLandeo observó el mismo fenómeno en Perú, por lo que para él la minería provoca "la acumulación de bienes que antes no eran vistos como parte del mercado" (2012: 67). De manera similar y producto de este tipo de hechos, se produjo una matanza en agosto del 2013 en la aldea indígena San Francisco de Locomapa, en la cual tres manifestantes Tolupanes perdieron la vida por defender su territorio; todos ellos eran miembros de su propia tribu indígena.

Estas ilustraciones demuestran que las relaciones "balanceadas" sociedad-naturaleza en las comunidades rurales no son inherentes, como sugiere Almendarez. La entrada de una compañía con una lógica capitalista de valor monetario y escasez puede provocar un cambio profundo en estas relaciones cuando provee incentivos de carácter privado, los cuales se tornan conflictivos con el interés colectivo. Además, entre los pueblos indígenas, campesinos y residentes urbanos existen diferencias internas y sus posiciones no son fijas, sino que están sujetas al cambio.

Sin embargo, ipor qué entonces hay tantas comunidades rurales dispuestas a defender su territorio? "La vida vale más que el oro", el argumento básico del movimiento antiminero enseña a los líderes comunitarios que la minería, en especial a cielo abierto, seca y contamina las fuentes de agua. Por ejemplo, en la parte rural de Honduras, más del 90 por ciento de los hogares no tiene acceso al agua potable (Herrera, 2013), por lo que dependen de los ríos y quebradas locales para todas las actividades diarias. Así, las vidas y el sustento de las comunidades están determinados por la presencia o ausencia de este líquido. Entonces, sus perspectivas siguen siendo una construcción social, aunque se basen en necesidades reales.

Al visitar a una comunidad Pech, ${ }^{16}$ se le alertó de que un ranchero cercano estaba negociando con una compañía minera. La primera reacción del dirigente de la comunidad fue de incredulidad: "No se puede por la razón de que es una zona boscosa. Es una zona donde fluyen las fuentes de agua. ¿Cómo vamos a hacer que se acepte esto? ¡Es imposible!” (comunicación personal, 8 de octubre del 2013). La comunidad indígena estaba consciente de sus derechos territoriales y no se había otorgado ninguna concesión minera en su territorio. No obstante, el agua afectada por la explotación en la parte más alta del río arriba fluye cerca de ellos. La presencia 
del agua como base de la vida se encuentra internalizado: "Va a matar...como una medicina letal de muerte lenta. Si nos quitan el agua, es como si nos quiten nuestro oxígeno", señala un líder de una comunidad campesina del área indígena (comunicación personal, 8 de octubre del 2013).

Figurativamente, si una persona vende su tierra, cien personas toman agua contaminada. Este problema fundamental de la minería le da fuerza a la oposición, pues se emplea para movilizar a comunidades enteras y para presionar a los dueños a no vender.

A nivel comunitario, a menudo se escucha el mismo argumento cuando los pobladores presionan a sus vecinos para estar unidos:

No piensen en el dinero que están ofreciendo. No piense solamente en esta gran cantidad de dinero que va a arrancar. Piensen en un pueblo que está atrás. Sus hijos, y todos que están cerca de esta comunidad. Porque no solo va a ser afectada esta comunidad. Va a ser afectado el municipio en general. (...) piensen, nuevamente les digo, en las personas que están atrás. ¿Cómo lo vamos a lograr? Solo estando unidos, haciendo conciencia los unos a los otros. El dinero es algo que se termina. Pero este liquido vital, el agua, que todos necesitamos, y después de esto vienen las grandes enfermedades. Nosotros entonces tenemos que tener cuidado, pensemos, y que queremos un futuro mejor para nuestro país. Y hay que decir no a la minería (comunicación personal, 25 de octubre del 2013).

El agua cruza las fronteras de la propiedad privada, de municipios, de territorios indígenas semiautónomos. Esta realidad sirve como instrumento discursivo fuerte para el movimiento antiminero: agua, necesidad para la vida, fluye por y conecta a las diferentes comunidades. Swyngedouw ha concluido que el agua tiene un papel clave en los conflictos mineros, pues "es un elemento 'híbrido' que captura y encarna procesos que a la misma vez son materiales, discursivos y simbólicos" (2004: 28).

Esto es cierto tanto para Honduras como para la región Andina, ya que el agua constituye una necesidad humana inalienable para el consumo y la producción agrícola, lo cual convierte a la minería en un competidor para la agricultura local y en una amenaza para el sustento campesino y su abastecimiento. Así, mientras asuntos estrictamente territoriales son de poco interés para las comunidades vecinas o urbanas (Bebbington et al., 2011), el agua funciona como un "pegamento" para los grupos que rechazan la minería.

Sin embargo, la disposición de las comunidades de oponerse a la minería también es producto de la desconfianza generalizada en los proyectos a gran escala y en el gobierno central. Como fue dicho por una activista de la MIGR en una capacitación:

Nosotros desconocemos los tratos que están haciendo los de arriba. Lo hacen en Tegucigalpa pero los que viven en los territorios somos nosotros. (...) Los dueños del territorio somos nosotros. 
Aunque allá están repartiendo el país como se reparte un pastel. jTenemos un congreso nacional que se ha quedado a repartir los bienes! (comunicación personal, 15 de julio del 2013).

Muchas comunidades rurales pueden vincular estas proclamaciones con sus propias memorias sobre la pérdida de patrimonio. En la Costa Norte, todos saben que los garífunas no han prosperado después de haber perdido su tierra en manos de la industria turística y bananera, por lo que ahora sus territorios se han dispersado y las playas son de propiedad privada. Se sabe que la existencia durante décadas de plantaciones de banano con capital extranjero no han traído prosperidad. El pueblo está consciente de las expropiaciones en el Bajo Aguán para desarrollar la industria de la Palma Africana y de las numerosas víctimas del conflicto agrario. Últimamente, además, hay un sentimiento común hacia "los grandes", ya que en Tegucigalpa nunca se han preocupado por el bienestar de la población rural: "No nos respetan como campesinos, ni en palabra ni en escrito", comentó un líder campesino. Mientras que otro durante una reunión expresó: "No hay desarrollo. Solo decepción". ¿Por qué la minería, de todas las industrias a gran escala, sería diferente?

Honduras es un país afectado por la violencia estructural (Cruz, 2011) y los altos niveles de corrupción (Honduras ocupa el lugar 140 de un total de 177 en el índice de corrupción de Transparency Internacional 2014), en donde mártires que murieron defendiendo su tierra -tanto figuras históricas como víctimas de luchas recientes- son recordados. Hablando a su comunidad, el presidente de un Patronato cerca de Trujillo proclama:

Les digo que luchemos. Luchamos con honor, así como hay muchos mártires también, nosotros tenemos nuestros próceres como Morazán y Lempira, que murieron defendiendo su tierra. Nosotros, hagamos lo mismo. Y si no podemos pues nos ponemos los sandalias como dice la Escritura de Jesús y sus discípulos, a vámonos para otro, para que no seamos contaminados (comunicación personal, 29 de octubre del 2013).

En este contexto, las memorias colectivas de las comunidades hondureñas han sido formadas; por lo tanto, no es sorprendente que el acto de movilización frecuentemente se enmarque como "la defensa del territorio" contra una "invasión". No obstante, a veces, se puede interpretar estas palabras de manera literal.

\section{Represalias contra la resistencia}

En Honduras, el activismo tiene serios riesgos. En el caso de la resistencia a la minería se pueden distinguir tres mecanismos de represalias: la criminalización del activismo, el uso de fuerza para reprimir manifestaciones y la amenaza (uso de la violencia). Además, diversas personas enfrentan la criminalización por parte de las autoridades. Un activista del Valle de Siria escribió: 
... te cuento que he estado criminalizado por mi lucha en la defensa de los recursos naturales y mucha persecución hacia mi persona pero seguimos en lucha compa (...) estoy valorando moverme un tiempo fuera de Honduras para bajar un poco la atención sobre mi persona (comunicación personal, 23 de marzo del 2014).

El Estado también utiliza la represión de la protesta como medida para expandir la frontera minera. En marzo de 2014, la policía militar intervino para liberar una carretera bloqueada por las comunidades de El Níspero frente a la instalación de una mina de óxido de hierro. En Azagualpa, un pueblo sometido desde hace años a la mina de San Andrés, en abril del 2014, se experimentó un surgimiento de resistencia por la defensa de su iglesia y cementerio -destinados a ser demolidos por la expansión inminente de la mina-. El ejército dispersó el bloqueo de la carretera hacia la aldea, mediante con golpes, balas y gas lacrimógeno.

Por tanto, activistas corren el riesgo de una amenaza que va más allá de la criminalización: la violencia. La intervención militar en El Níspero fue seguida por el asesinato brutal de Rigoberto López Hernández, en mayo del 2014. A López Hernández -miembro del Movimiento Ambiental Santabarbarense- le degollaron la garganta y le cortaron la lengua antes de volcar su cuerpo en un espacio público (Rights Action, 2014). Por su parte, activistas en el Bajo Aguán han recibido amenazas que ellos vinculan al gobierno municipal de Tocoa. En vez de hacerse conocidos públicamente, los activistas tratan de trabajar por hablar con la gente "puerta a puerta":

Es bien difícil porque sí para nosotros (...) facilitadores de un proceso de oposición a la minería trabajar en la región. Tenemos que cuidar nuestros pasos. Tener mucha cautela, mucha cautela. De repente vivir en lo anonimato, no se hace muy público, esa amenaza siempre va a existir. Va a existir.. la gente que está en las compañias mineras va a contratar a los poderosos, dedicados al asesinato, a amenazas. A la presión, o eso a perseguir las personas. Para que los movimientos que se levanten, se vayan disolviendo. Por las amenazas por la vida, pueden ver muertes. Las personas que hacen contratos con grupos de delincuentes, no tienen conciencia. (comunicación personal, 11 de julio del 2013).

Varios de estos proyectos tienen vínculos directos con el crimen organizado. En una acción coordinada por el DEA, ${ }^{17}$ el día 25 de septiembre de 2013, se llevó a cabo la Operación Neptuno, en la cual el Estado confiscó varias compañías pertenecientes al cartel de Los Cachiros, sumando un valor de unos 800 millones de dólares (El Heraldo, 2013). Estos negocios incluyen una plantación de palma africana, una rancha, un zoológico, un centro turístico, unas petroleras y una mina de carbón en el Bajo Aguán, denunciado desde mucho antes por un grupo de activistas locales de la MIGR. En Olancho, la MIGR también denunció la presencia de la narcominería. Como consecuencia de las amenazas, una activista se encerró en casa por dos semanas, pues temía salir. Sin embargo, ella lo vio como parte de su responsabilidad seguir denunciando lo que ocurre en su departamento: 
Nosotros continuamos con el tema aunque sabemos que es muy peligroso porque, no nos podemos morir dejando las comunidades, sin que se dan cuenta de los que está pasando. (...) es muy dura, muy pesada, pero hay que seguir. Y si me toca morir así ya me tocó. Si lo quiere Dios. Punto. Porque, porque si nosotros no hablamos, las piedras no van a hablar por mí. Yo tengo que hablar. Yo tengo que decir lo bueno y lo mal (comunicación personal, 17 de julio del 2013).

De todos modos, es importante señalar que, aunque se percibe a los narcomineros como más dispuestos a usar la violencia, los activistas que han enfrentado a otras empresas también sufren amenazas. La persistente intimidación y uso de violencia es causa de un ambiente de miedo sostenido, lo cual deja claro que el complejo extractivista hondureño no solamente utiliza publicidad o propaganda para empujar la frontera extractiva, pues la violencia es un instrumento esencial para la expansión de la industria minera. A pesar de todos los estándares de responsabilidad social empresarial, parece ser una forma de protección de mercado ampliamente usada en Honduras para manejar la oposición a proyectos de gran potencial económico.

En este contexto, no se considera la militarización en el Bajo Aguan como una respuesta a la presencia de las organizaciones criminales armadas (como es el discurso del Gobierno), sino como medida para proteger los intereses económicos que están desarrollándose ahí: palma africana, proyectos hidroeléctricos y minería. En el caso específico de la minería, la tasa de seguridad establece un vínculo financiero directo entre las fuerzas armadas estatales y las empresas mineras. Esta situación corresponde con lo que Garay-Salamanca y Salcedo-Albarán (2011) definen como "captura del Estado" (una forma de corrupción sistemática en la que individuos o firmas privadas cooperan con el Estado para obtener beneficios económicos privados, en detrimento del bienestar social de la población).

Por otro lado, la debilidad y la corrupción estatal permiten la proliferación de fenómenos como la existencia de grupos armados/sicarios y la narco minería. El interés del narcotráfico en la minería requiere más investigación, pero yo sugiero que va más allá del lavado de activos y expansión de capital hacia la economía formal. Como la minería, el narcotráfico requiere un control de territorio: la obtención de concesiones mineras en territorios remotas es una estrategia para ejercer control de forma legal.

\section{Conclusiones}

\section{El complejo extractivista}

Para esta investigación se ha aplicado el concepto de "complejo extractivista", es decir, una alianza de la industria extractiva y las instituciones del Estado que gobiernan a la minería. Sin embargo, también incluye el aparato de seguridad del estado (la policía y el ejército), grupos criminales, los medios de comunicación masivos, 
además de los tratados y estándares que dan forma a la minería, como lo es la responsabilidad social empresarial. El primer empuje de la frontera minera fue el intento del Gobierno hondureño para crear una economía nacional basada en la exportación de minerales con la introducción de la Ley General de Minería en 1999, el cual fue frenado por el movimiento antiminero. El segundo empuje se puso en marcha después del golpe de Estado de junio de 2009 -una repetición de la doctrina de choque-.

El cuadro discursivo emitido por el complejo extractivista incluye promesas de empleos bien pagados, discursos de desarrollo infraestructural o servicios sociales, desarrollo sostenible y representación de la minería como la "salvación de Honduras". Cuando resulta insuficiente el marco discursivo, los propulsores de la industria pueden recurrir a la amenaza y luego a la violencia -por fuerzas tanto públicas como privadas- para imponer proyectos mineros. Estos actos son contraproductivos en el sentido de que proveen una legitimación de la lucha antiminera (no menos importante mediante la creación de mártires), pero representan una amenaza seria para el trabajo de aquellos comprometidos en la resistencia.

\section{El movimiento antiminero}

El movimiento antiminero surgió como respuesta a los impactos generados por la expansión de la industria minera hacia tierra hondureña -principalmente por su comportamiento invasivo y los impactos ambientales y de salud en el Valle de Siria. Su resistencia siempre ha involucrado una amplia gama de actividades, incluyendo demandas de inconstitucionalidad, denuncias (internacionales) y movilizaciones de protesta. Sus logros iniciales fueron deshechos por el golpe de Estado del 2009.

Hoy en día, la minería es un tema sumamente politizado, lo cual se debe a la forma abrupta en que el Gobierno interino deshizo todas las avances del movimiento antiminero en un tiempo de crisis y a la posición explícita del Gobierno postgolpe para fomentar la industria minera. Como menciona Calderon et al. (1992) y Foweraker (2001), los movimientos sociales usualmente toman una posición (más o menos permanente) de desconfianza contra el Gobierno central. Con certeza, ese es el caso del movimiento antiminero hondureño, hasta el punto de que el consenso ya no es viable.

En todo caso, el movimiento antiminero enmarca su oposición a la minería como "defensa de la vida", un discurso sin afiliación política en un país políticamente polarizado. Svampa (2011) identificó cuatro narrativas en su mayoría usadas por los movimientos antimineros en América Latina, entre ellas la protección de propiedad comunal, la justicia ambiental en términos de sustentabilidad y generaciones futuras, la ideología ecuatoriana de buen vivir y la justicia ecológica (la protección de las especies y los ecosistemas). En Honduras, la resistencia se enfoca en la protección de los recursos comunales, lo cual también implica una revalorización de las relaciones entre sociedad y naturaleza, pues sus defensores consideran un ambiente sano como 
un requisito para el bienestar humano. Algunos han hecho explícita esta visión, al reemplazar el concepto "recurso natural" por el de "bienes naturales" para describir al agua y al bosque, con el argumento de que no se puede o no se debería poner un precio de mercado o "explotar" estos elementos que son requisito para el bienestar humano.

El agua es una necesidad para la vida y la vida vale más que el oro. Esta lógica es el marco principal (Steinberg, 1998) del movimiento y resuena con la experiencia cotidiana de las comunidades rurales que dependen de las fuentes de agua. Para ellas, el acceso a este recurso y a la tierra es una necesidad para la continuación de su modo de vida. Además, el poder simbólico del agua va más allá de las comunidades directamente afectadas, pues llega a las comunidades y ciudades cercanas, lo cual explica la capacidad del movimiento para movilizar miles de personas en diferentes contextos.

Este marco es fundamentado en el Valle de Siria, un símbolo para la salud debido a los impactos causados por la contaminación del agua. La desconfianza generalizada hacia el Estado y los proyectos de gran escala que fomenta, también contribuyen al rechazo de la minería. Este sentimiento viene tanto de la memoria colectiva de la sociedad hondureña sobre el papel que han jugado las compañías bananeras y otros proyectos en la alteración de el curso de la historia hondureña, como también del contexto de impunidad que influye en la vida cotidiana. Comunidades comprometidas en una lucha antiminera dan significado a ella conforme su identidad campesina, enmarcando la resistencia en términos de "defensa de territorio" o "defensa de patrimonio".

No obstante, las comunidades no están simplemente sujetas a la intervención de las organizaciones antimineras, pero activamente buscan estas alianzas, lo cual se relaciona con la percepción de que una comunidad sin apoyo externo no puede ganar una lucha antiminera. Ante esto, los movimientos sociales y las ONG actúan como puentes que cuentan con una red internacional, pues tienen la capacidad de escalar la resistencia estratégicamente, traduciendo "defensa de territorio" por "defensa de derechos humanos". La magnitud de la resistencia crece mientras la lucha madura desde el nivel comunitario, en organizaciones cercanas, hacia la comunidad internacional. Especialmente cuando defensores de la mina están dispuestos a usar medidas ilegales para perseguir sus intereses, aumentar la resistencia involucrando actores internacionales (especialmente organizaciones de derechos humanos) podría llegar a ser la única manera de prevenir la instalación de una mina en el territorio.

\section{El cabildo abierto versus la consulta}

El movimiento antiminero se enfoca en la movilización de comunidades en la "defensa de territorio". Visitan a las comunidades con concesiones mineras para enseñar a líderes comunitarios -notablemente Patronatos y Juntas de Agua- sobre los 
impactos de la minería, a través de talleres de capacitación y excursiones al Valle de Siria, y sobre los derechos legales que una comunidad tiene para rechazar un proyecto minero vía consulta pública. Sin embargo, en vez de enfocarse en la consulta establecida por ley, se organizan cabildos abiertos independientes, por medio de los cuales se presiona al gobierno local a declarar el municipio libre de minería. La diferencia crucial entre los dos es que la consulta se realiza en el campo de juego del complejo extractivista: no es previo ni libre. En cambio, las comunidades ejercen más autonomía en el referéndum preventivo.

En pocas palabras, la consulta está sujeta a manipulación. Se lleva a cabo la consulta ex post a la instalación de la mina: la compañía arriesga perder una inversión considerable. La fase de explotación comienza meses o hasta años después de las exploraciones iniciales, dando a las compañías mineras y otros beneficiarios de la explotación minera un margen considerable para convencer o coaccionar a las comunidades en aceptar el proyecto. Esto incluye desde discursos de progreso y beneficios para líderes, hasta criminalización, intervención militar, amenazas y violencia hacia oponentes claves.

El movimiento antiminero está consciente de esto. Por lo tanto, se enfoca en la movilización de comunidades ex ante de la instalación de una mina de manera preventiva. Fuera del campo de juego del complejo extractivista, se crea otra arena donde las comunidades involucradas pueden ejercer su autonomía. Sin embargo, tomando en cuenta que la ley minera, específicamente, dice que "no se puede declarar ninguna área permanentemente libre de minería", aún está por verse qué fuerza legal tienen las declaraciones para la 'defensa del territorio'.

\section{Consideraciones teóricas}

Una sola teoría no es suficiente para explicar los motivos, acciones, éxitos y obstáculos de un movimiento social. La teoría de enmarque puede ser útil para el análisis de la percepción de la realidad, pero no se puede asumir que puede explicarla completamente, pues para llegar a un entendimiento más profundo es necesario usar diferentes enfoques de forma complementaria. En esta investigación, se intentó mirar más allá de los marcos discursivos de acción colectiva y otros recursos disponibles (materiales, humanos y culturales), tomando en cuenta la estructura de oportunidades y restricciones políticas en la cual se encuentra el movimiento, así como el repertorio de contracciones de los oponentes del movimiento.

La teoría de enmarque ha demostrado ser muy útil en explicar el éxito del movimiento antiminero con las comunidades involucradas: el marco discursivo del movimiento de la resistencia contra la minería como una defensa del agua y la vida conecta muy bien con la cotidianeidad de las comunidades. Mientras este marco discursivo permite una interacción cooperativa con las comunidades, 
los marcos opuestos (lo del complejo extractivista y lo del movimiento antiminero) son una fuente de conflicto. Para traer de vuelta la teoría de enmarque a sus raíces en el análisis de discursos, el conflicto por la minería no es solamente un conflicto sobre recursos, sino también un conflicto por la verdad. En un sentido Foucaultiano, verdad es poder (Foucault, 1977); así, el movimiento antiminero es poderoso en el sentido de que "su verdad" tiene mejor resonancia con las experiencias de las comunidades que "la verdad" del complejo extractivista, a pesar de que el último cuenta con un aparato de propaganda considerable.

No obstante, la teoría tiene sus límites. Quisiera dar un ejemplo que muestra cómo es posible integrar el enfoque de enmarque con los enfoques de "movilización de recursos y estructura de oportunidades políticas" hacia los movimientos sociales, los cuales necesitan cuadros de acción colectiva convincentes para movilizar al pueblo en protestas. Estas a su vez son manifestaciones del poder duro del movimiento usadas para ejercer influencia y ampliar oportunidades políticas, donde los cuadros discursivos en sí mismos no alcanzan para realizar avances.

Ahora bien, se puede considerar el poder discursivo como un poder blando o poder normativo (Sell, 1996; Reimann, 2006). Tanto el complejo extractivista como el movimiento antiminero carecen de poder normativo vis-à-vis, pero este posee un poder duro o represivo considerable (medidas que implican la amenaza o uso de violencia). El análisis de enmarque no explica el uso de violencia, ya que no convence a un grupo meta, pero lo coacciona a someterse a través de la militarización, las amenazas o la represión. La violencia es la continuación de políticas y negocios donde el diálogo falla (disciplinar a través del castigo). Muestra que hay más en juego que un marco discursivo poderoso en explicar el éxito de un movimiento o contramovimiento: coaccionar por medio del ejercicio de poder duro se convierte en una alternativa viable al enmarque cuando no hay suficiente credibilidad.

Tomando en cuenta lo anterior, se puede ver los bloqueos de carretera o las manifestaciones al nivel de los municipios como una manifestación del poder duro del movimiento, utilizado cuando su cuadro discursivo no logra convencer al mundo político formal. Entonces, el uso de fuerza -ya sea manifestaciones o violencia- es un recurso utilizado cuando el discurso (otro recurso) en sí no es suficiente para sobrepasar un impasse.

En cuanto al enfoque de estructura de oportunidades políticas, el caso de la oposición a la minería en Honduras contradice la presunción de que una posición reformista es más exitosa que una posición opositora y cuestiona la rigidez y las capas de las estructuras de oportunidad política. La historia de la AC versus la ACD es una en que la plataforma con una posición más intransigente es más exitosa que la plataforma dispuesta a negociar su punto de vista. Sostengo que se puede explicar esto por la capacidad de la ACD de ampliar sus oportunidades políticas a través de la movilización de masas -el uso estratégico de su "poder duro" para ampliar sus oportunidades políticas-. 
No obstante, en Honduras después del golpe de estado, - donde movilizaciones a gran escala ya no alcanzan para lograr un dialogo -el movimiento necesitará movilizar apoyo internacional para presionar al Estado- al menos para lograr una mejora en el campo de protección de derechos humanos básicos.

\section{Notas}

1 Asociación de Organismos No Gubernamentales; Mesa Nacional para la Incidencia de Gestión del Riesgo.

En los departamentos de Copán, Ocotepeque, Santa Bárbara, Cortés, La Paz, Colón, Yoro, Olancho, y Choluteca.

Prohibido en Honduras.

Comités comunitarios encargados para asegurar el acceso de las comunidades al agua potable.

$173 \mu \mathrm{g} / \mathrm{dL}$ de plomo, de $263 \mu \mathrm{g} / \mathrm{dL}$ de arsénico. Niveles aceptadas de plomo y arsénico oscilan entre 10 y 30 g/dl; niveles arriba de $100 \mu \mathrm{g} / \mathrm{dl}$ son consideradas críticos (Herrera, 2013).

Dirección Ejecutiva de Fomento a la Minería: el instituto encargado con el doble papel de fomentar y regular la minería.

Hoy en día llamado INHGEOMIN: Instituto Hondureño de Geología y Minas.

ICMM (Consejo Internacional de Minería y Metales), UN Global Impact, EITI (Iniciativa de Transparencia de las Industrias Extractivas), Negocio por Responsabilidad Social, Principios Voluntarios de Seguridad y Derechos Humanos, y el Código Internacional de Manejo de Cianuro.

Los vecinos de la comunidad dicen que no conocen a la gente del promocional de Goldcorp, y afirman que el hotel de eco-turismo está tripulado por empleados de otras partes.

Coalición Nacional de de Redes Ambientalistas de Honduras.

Incluyendo Santa Bárbara, Atima, Colinas y San Francisco de Ojuera en Sánta Barbara; Chinaclas y San José de la Paz; Belén Gualcho en Ocotepeque, Yorito y El Negrito en Yoro, Juticalpa y Olancho en Olancho, Danlí y Teupasenti en El Paraíso, Jesús de Otoro en Intibuca, y Saba en Colón.

Movimiento Amplio por la Dignidad y Justicia. 


\section{Bibliografía}

Acosta, Alberto. Extractivismo y neoextractivismo: dos caras de la misma maldición, 2012. Web.

Almendarez, Juan. Cover-up \#1: Goldcorp (Entre Mares) \& the government of Honduras hide information about poisoning of children and adults. Madre Tierra, Nov. 2011. Web.

Almendarez, Juan. Honduras: la resistencia contra la industria minera. Madre Tierra, May. 2006. Web.

Aráoz, A.M. “El Auge de la Minería Transnacional en América Latina. De la ecología política del neoliberalismo a la anatomía política del colonialismo". En La Naturaleza colonizada: ecología política y minería en América Latina. Coord. H. Alimonda. Buenos Aires: CLASCO, 2009. 135-80.

Bebbington, A.; Bebbington, D.H.; Bury, J.; Lingan, J.; Muñoz, J.P. y Scurrah M. "Mining and Social Movements: Struggles Over Livelihood and Rural Territorial Development in the Andes". World Development 36, 12 (2007): 2888-2905.

Bebbington, A. y Valencia, L.H. "Conclusiones: minería, neoliberalisación, y reterritorialización en el desarrollo rural". En Minería, movimientos sociales y respuestas campesinas: una ecología politica de transformaciones territoriales. Ed. A. Bebbington. Lima: IEP y CEPES, 2007. 285-314.

Bebbington, A.; Humphreys Bebbington, D. y Bury, J. "Federating and Defending: Water, Territory and Extraction in the Andes". En Out of the Mainstream: water rights, politics, and identity. Eds. R. Boelens, D. Getches, y A. Guevara-Gil. Routledge, London, 2011. 307-327.

Bebbington, A. "Extractive Industries, socio-environmental conflicts, and political economic transformations in Andean America". En: Extractive Industries, Social Conflict and Economic Development: Evidence from South America. Routledge: London, 2012. 3-26.

Benford, R.D, y Snow, D.A. "Framing Processes and Social Movements: an Overview and Assessment". Annual Review of Sociology 26 (2000): 611-39.

Bianchini, Flaviano. Estudio técnico: contaminación del agua en el área de explotación minera del proyecto San Martin, en el Valle de Siria y repercusiones sobre la salud humana. Mining Watch Canada, Jul. 2006. Web.

Bridge, G. "Contested Terrain: Mining and the Environment". Annual Review of Environmental Resources 29 (2004): 205-259.

Canel, E.; Idemudia, U. y North, L. "Rethinking Extractive Industry: Regulation, Dispossession, and Emerging Claims". Canadian Journal of Development Studies 30 (2010): 1-2, 5-25.

Calderón, F.; Piscitellli, A. y Reyna, J.L. "Social Movements: Actors, Theories, Expectations". En: The Making of Social Movements in Latin America. Escobar, A. y Alvarez, S. San Francisco y Oxford: Westview Press, 1992. 19-36.

"CESPAD". (2011). La percepción de la ciudadanía hondureña sobre los impactos de la minería metálica. Hallazgos principales de la encuesta de opinión ciudadana en septiembre 2011. CESPAD, Nov. 2011. Web.

Coumans, C. "Alternative Accountability Mechanisms and Mining: The Problems of Effective Impunity, Human Rights, and Agency". Canadian Journal of Development Studies 30 (2010): 1-2, 27-48.

Cruz, J.M. "Criminal Violence and Democratization in Central America: The Survival of the Violent State". Latin American Politics and Society, 53 (2011): 4.

El Heraldo. Operación Neptuno confisca propiedades de los Cachiros. El Heraldo, Oct. '2013. Web. 
Escobar, A. Territories of Difference: place, movements, life, risks. Durham y London: Duke University Press, 2008.

Foucault, M. "Truth and Power". En Contemporary Sociological Theory, Craig Calhoun et al. Oxford: Blackwell Publishing Ltd. 2005: 201-209.

Foweraker, J. "Grassroots Movements and Political Activism in Latin America: A Critical Comparison of Chile and Brazil". Journal of Latin American Studies 33, 4 (2001): 839-865.

Fulmer, A.M.; Godoy, A.S. y P. Neff. “Indigenous Rights, Resistance, and the Law: Lessons from a Guatemalan Mine". Latin American Politics and Society 50, 4 (2008): 91-121.

Harvey, David. El "nuevo" imperialismo: acumulación por desposesión. Socialist Register, 2004. Web. Garay-Salamanca, L.J. y E. S. Salcdo-Albarán. "Institutional impact of criminal networks in Colombia and Mexico". Crime, Law and Social Change 57 (2012): 177-194.

Giddens. A. "Agency, Structure". En Contemporary Sociological Theory. Eds. Craig Calhoun et al. Oxford: Blackwell Publishing Ltd, 2005. 231-242.

Gleditsch, K.S. y Ruggeri, A. "Political opportunity structures, democracy, and civil war". Journal of Peace Research 47 (2010): 299-310.

"Goldcorp". Goldcorp Receives Top Sustainability Ranking in Canada. Goldcorp, Jun. 2015. Web.

"Goldcorp". Goldcorp named to NASDAQ Global Sustainability Index. Goldcorp, Dec. 2015. Web.

"Goldcorp". Goldcorp named to Dow Jones Sustainability Index North America. Goldcorp, Sep. 2012. Web.

"Goldcorp". Responsible Mining. Goldcorp, s. f. Web.

Haarstad, H. y Floysand, A. "Globalization and the power of rescaled narratives: A case of opposition to mining in Tambogrande, Peru", Political Geography 26, 3 (2007): 289-308.

Herrera, F. La mina San Martín en el Valle de Siria. Exploración, explotación y cierre: impactos y consecuencias. Informe ejecutivo. Tegucigalpa: IDAMHO, Gráficos, 2013.

"INHGEOMIN". Concessiones otorgadas, actualizado al 31 de julio de 2015. INHGEOMIN, 2015. Web.

Jamasmie, C. Lack of mining law costs Honduras US\$3 billion, Mining.com, 2012. Web.

Jarvis, A. y Amezaga, J. "Technical Review of mine closure plan and mine closure implementation at Minerales Entre Mares San Martin mine, Honduras. A report prepared for Caritas (Honduras) / CAFOD International", June 2009. Web.

"Latin America Advisor". "Will this be the 'year of mining' for Central America? ", Latin America Advisor, ene. 2015. Web.

Melucci, A. y Avritser, L. “Complexity, cultural pluralism and democracy: collective action in the public space. Social Science Information 39, 4 (2000): 507-527.

Moore, J. “Canada's Mining Indusry y Corporate Social Responsibility". Community Networks, 2012. Web.

Newson, L. "Labour in the Colonial Mining Industry of Honduras". The Americas 39, 2 (1982): 185-203.

Peluso, N.L. y Lund, C. “New frontiers of land control: Introduction". Journal of Peasant Studies 38, 4 (2011): 667-681.

Reimann, K. D. "A view from the Top: International Politics, Norms and the Worldwide Growth of NGO's". International Studies Quarterly 50 (2006): 45-67.

"Rights Action". Brutal, Public Murder of Anti-mining, Community and Environmental Defender in Honduras. Rights Action, 2014.

"OXFAM". La Minería de Metales en Centroamérica: Dolor y Resistencia. Oxfam América, 2008. Web. 
Roldan, C. F y Purvance, D. San Martín mine in Honduras - From Closure to Sustainability, Goldcorp, 2011. Web.

Sell, S. K. "Structures, agents and institutions". En Private corporate power and the globalization of intellectual property rights. Cambridge: Cambridge University Press, 1996. 91-106.

Sosa, M. y M. Zwarteveen. "Acumulación a través del despojo: el caso de la gran minería en Cajamarca, Perú". En Justicia hídrica: acumulación, conflicto y acción social. R. Boelens, L. Cremers, y M. Zwarteveen. Lima: EIP y CEPES, 2012. 381-392.

Steinberg, M.W. "Tilting the Frame: Considerations on Collective Action Framing from a Discursive Turn". Theory and Society 27, 6 (1998): 845-872.

Svampa, M. "Extractivismo neo desarrollista y movimientos sociales: ¿Un giro eco-territorial hacia nuevas alternativas?". En Más allá del desarrollo. Ed. S. Jarrín. Quito: Editorial El Conejo, 2011. 185-218.

Swyngedouw, E. Social Power and the Urbanization of Water: Flows of Power. Oxford: Oxford University Press, 2004.

"Transparency International". Transparency Internacional. 2016. Web.

Urkidi, L. "The Defence of Community in the Anti-Mining Movement of Guatemala". Journal of Agrarian Change 11, 4 (2011): 556-580.

Van de Sandt, J. Mining Conflicts and Indigenous Peoples in Guatemala. Cordaid, 2009. Web.

Watts, M. y Peluso, N. "Resource Violence". En Critical Environmental Politics. Ed. C. Death. London: Routledge, 2014. 184-197.

Yagenova, S.M.; García, E.; García, R. y W. Santa Cruz. Los movimientos sociales y el Poder: concepciones, luchas y construcción de contrahegemonía. Guatemala: FLACSO, 2010.

Youtube. "Goldcorp's San Martin Mine Reclamation in Honduras", 2011. Web.

Zibechi, R. Los movimientos sociales latinoamericanos: tendencias y desafíos. Observatorio Social de Latinoamérica, 2003. Web.

Nick Middeldorp. Neerlandés, obtuvo su maestría en Estudios de Desarrollo Internacional por la Universidad de Wageningen, Países Bajos. Ha realizado investigaciones para la ONG PAX y para el Instituto Interamericano de Derechos Humanos (IIDH) acerca de las empresas bananeras y paramilitares en Colombia, y el derecho a la consulta previa, libre e informada (CPLI) de los pueblos indígenas. Actualmente está desempeñando una investigación para la ONG Both Ends acerca del proceso de consulta con la población Rama-Kriol, con respeto al Gran Canal Interoceánico de Nicaragua. Es coautor con Rosembert Ariza e Irma Velazquez Nimatuj del libro El derecho a la consulta previa, libre e informada: una mirada crítica desde los pueblos indígenas (2016).

Contacto: Nick.middeldorp@gmail.com 